\title{
BMJ Open Being normal, not vulnerable: case study of a 2-day residential programme for young adults with cancer
}

\author{
Ana Martins, ${ }^{1}$ Rachel M Taylor, ${ }^{1}$ Sue Morgan, ${ }^{1,2}$ Lorna A Fern ${ }^{1}$
}

To cite: Martins A, Taylor RM, Morgan S, et al. Being normal, not vulnerable: case study of a 2-day residential programme for young adults with cancer. BMJ Open 2017;7:e015309. doi:10.1136/ bmjopen-2016-015309

\section{- Prepublication history and} additional material for this paper are available online. To view these files please visit the journal online (http://dx.doi. org/10.1136/bmjopen-2016015309).

Received 24 November 2016 Revised 24 March 2017 Accepted 9 May 2017

CrossMark

${ }^{1}$ University College London Hospitals NHS Foundation Trust, London, UK

${ }^{2}$ Leeds Teaching Hospitals NHS Foundation Trust, Leeds, UK

Correspondence to

Dr Ana Martins; ana.martins1@ nhs.net

\begin{abstract}
Objectives To identify and describe the outcomes and facilitating processes of participation at 'Find Your Sense of Tumour' (FYSOT), a 2-day residential programme/conference for young people with cancer, from the perspective of professionals attending and patient representatives.

Design Case study.

Setting Observation of the 'Find Your Sense of Tumour' over 18 s residential programme and face-to-face interviews in hospital and phone interviews.

Participants Twenty-six participants - 19 professionals from hospitals across the UK who accompanied young people to FYSOT; 3 programme organisers; and 4 young people from the programme steering committee.

Methods Participant observation and semistructured interviews.

Results This process evaluation of an educational, social and peer-to-peer support residential weekend for young people with cancer identified key outcomes for young people - positive attitudes (increased sociability, confidence), belonging (feeling accepted, understood), recreation (trying new activities, having fun) and increased knowledge (balance between educational talks and interactions with other young people); and three overarching facilitating processes — being with other young people, the professionals accompanying young people to the event for support and guidance, and the conference/intentional programming. Being in a safe, relaxed and fun environment with other young people facilitates the development of peer support networks and increases young people's confidence and knowledge. Although the focus of the residential programme is on young people, interviewees acknowledge the impact of attending on professionals' motivation, learning and changes in practice.

Conclusions This study has extended our understanding of the role of residential programmes by identifying outcomes and facilitating mechanisms. We have shown that residential programmes have an important role in providing participants with social, emotional and informational support, as well as play an important role in redefining normality. Longitudinal quantitative and qualitative research is needed to optimise outcomes and design and implement quality programmes that support young people's development.
\end{abstract}

\section{INTRODUCTION}

Young people face rapid developmental changes. A cancer diagnosis, treatment and side effects pose a unique set of psychosocial challenges during this period. ${ }^{12}$ Additional challenges presented by their disease include
Strengths and limitations of this study

- Our study was based on a large residential programme encompassing the range of cancer types occurring in young people.

- Attendance at the residential programme is free to young people aiming to be fully inclusive and limit socioeconomic bias.

- Participants represented a range of professionals, nationally across four UK nations.

- Observations were made by a single researcher; however, involvement of the team in analysis and interpretation of the data limited bias and confirmed the processes and outcomes of the programme.

- The observation was based on the over $18 \mathrm{~s}$ programme, so it may not reflect the processes and outcomes for the under 18-year-old event.

understanding their diagnosis and treatment-related side effects, ${ }^{3}$ fear of recurrence, worry about body image, ${ }^{4}$ sexual identity and fertility, ${ }^{5}$ becoming independent of their families, and altered experience of education/ employment (eg, educational disadvantage and delayed preparation for higher education or career goals due to school absence). ${ }^{6}$ Furthermore, extended periods of hospitalisation, multiple clinic visits and recovery mean young people miss out on social and learning opportunities. ${ }^{7}$ Isolation impacts on young people's skills development ${ }^{8}$ and leaves them with potentially limited opportunities to learn how to cope with the physical, psychological and social difficulties that accompany their cancer diagnosis. ${ }^{78}$ A review of social well-being in young people with cancer reported greater challenges in social functioning compared with the general population and when compared with younger and older patients with cancer. ${ }^{1}$

Peer support from other cancer survivors may be important for transition to cancer survivorship and validating survivors' emotional and cognitive needs. ${ }^{9}$ This premise has informed the development of residential support programmes (eg, 
recreational summer camps). ${ }^{10}{ }^{11}$ For example, a residential programme for children with cancer reported support, understanding, encouragement, acceptance and learning about their illness and treatment in those attending. ${ }^{12}$ The importance of the relationships developed during programmes, due to the shared significant common experience of a cancer diagnosis for those attending, was also reported. ${ }^{13}$

\section{Residential programmes for young people}

Since the 1980s camps/residential programmes have been used to promote successful accomplishment of developmental life stages for children and young people with cancer. ${ }^{14}$ An increasing number of programmes exist; however, evaluation of what works, outcomes affected and why is not fully described. ${ }^{715}$

Studies based on residential programmes in younger adolescents with cancer and children with chronic diseases have suggested improved self-esteem, developing connections with other young people, togetherness and creating memories ${ }^{16}$; social acceptance, physical appearance, global self-worth and decrease in loneliness ${ }^{17}$; increased positive attitudes and respite ${ }^{18}$; improved body image, self-compassion and self-esteem; and reduction in depression and alienation. ${ }^{8}$ Research has shown changes following residential programmes do not necessarily occur in a linear, positive fashion (eg, outcome differences by subgroups such as age, gender) so there is a need for process and outcome evaluations to understand how specific aspects of residential programmes optimise outcomes. This would allow organisers to design and implement quality programmes that support young people's development. ${ }^{715}$

To date there has been limited systemic evaluation of residential programmes for young adults with cancer.

\section{Aims of the current research}

'Find Your Sense of Tumour' (FYSOT; table 1; online supplementary appendix 1 for detailed plan) is a 2-day residential programme with educational presentations, motivational speakers, workshops and social events for young people with cancer. ${ }^{19}$ Despite some evidence of a positive experience at the residential programme (Teenage Cancer Trust personal communication, 2014), this has never been systematically investigated, and the process and factors influencing these positive outcomes are not known.

\section{METHODS}

\section{Design}

We undertook a case study, thought to be particularly useful to investigate phenomena occurring within reallife contexts. ${ }^{20}$ We focused on the uniqueness of the case, particular context, issues and story ${ }^{21}$ through participant observation of the over 18s FYSOT and semistructured interviews.

\section{Setting}

The observations were conducted at the residential programme (table 1); self-reported demographics of young people attending the conference can be seen in table 2. Interviews were conducted over the telephone or face to face in the hospital.

Not all participants answered all questions, and the percentages shown are proportional to the numbers of patients who answered each question.

\section{Participants}

A convenience sample of 19 professionals from 19 UK hospitals ( 7 healthcare professionals and 12 youth support coordinators) who accompanied young people to FYSOT, 3 programme organisers and 4 young people from the programme steering committee took part in individual interviews (total $\mathrm{n}=26$ ). Professionals' experience of the residential programme varied, six were first-timers, and thirteen had attended previously between two and eight times. Young people on the programme steering committee had been to the residential programme twice as participants before being part of the steering committee, thus had attended three or more times before the interview. The role of the professionals at the conference is to provide safe guarding and support for the young people attending in their group.

\section{Procedure}

An independent researcher (AM) attended and observed FYSOT. No young person was approached or asked to engage with the researcher. Professionals were informed that a researcher would be observing FYSOT, who in turn informed young people. All participants knew that if they did not want the researcher present at any point during the programme they could inform their group leader/ programme organiser. The researcher was not asked to leave at any point over the weekend.

Following the observations, professionals, organisers and young people from the programme steering committee were invited to take part in an individual interview (in order to be inclusive, 75 professionals were invited) by an 'opt-in' process. Only those who consented to having their contact details shared were contacted by the researcher to arrange an interview $(n=19)$. We did not collect any information on those who did not want to participate, and all those who consented completed an interview. Interviewees were sent the interview topic guide in advance. Twenty-three interviews were conducted over the phone and three interviews were conducted face to face. All participants were informed that participation was voluntary, consent was implicit and assumed when they agreed to do the interview. Consent was a continuous process and participants were reminded at the beginning of the interviews they could stop at any point.

\section{Data collection}

Interviewees shared their views of the residential programme, their experiences and reflections about how 


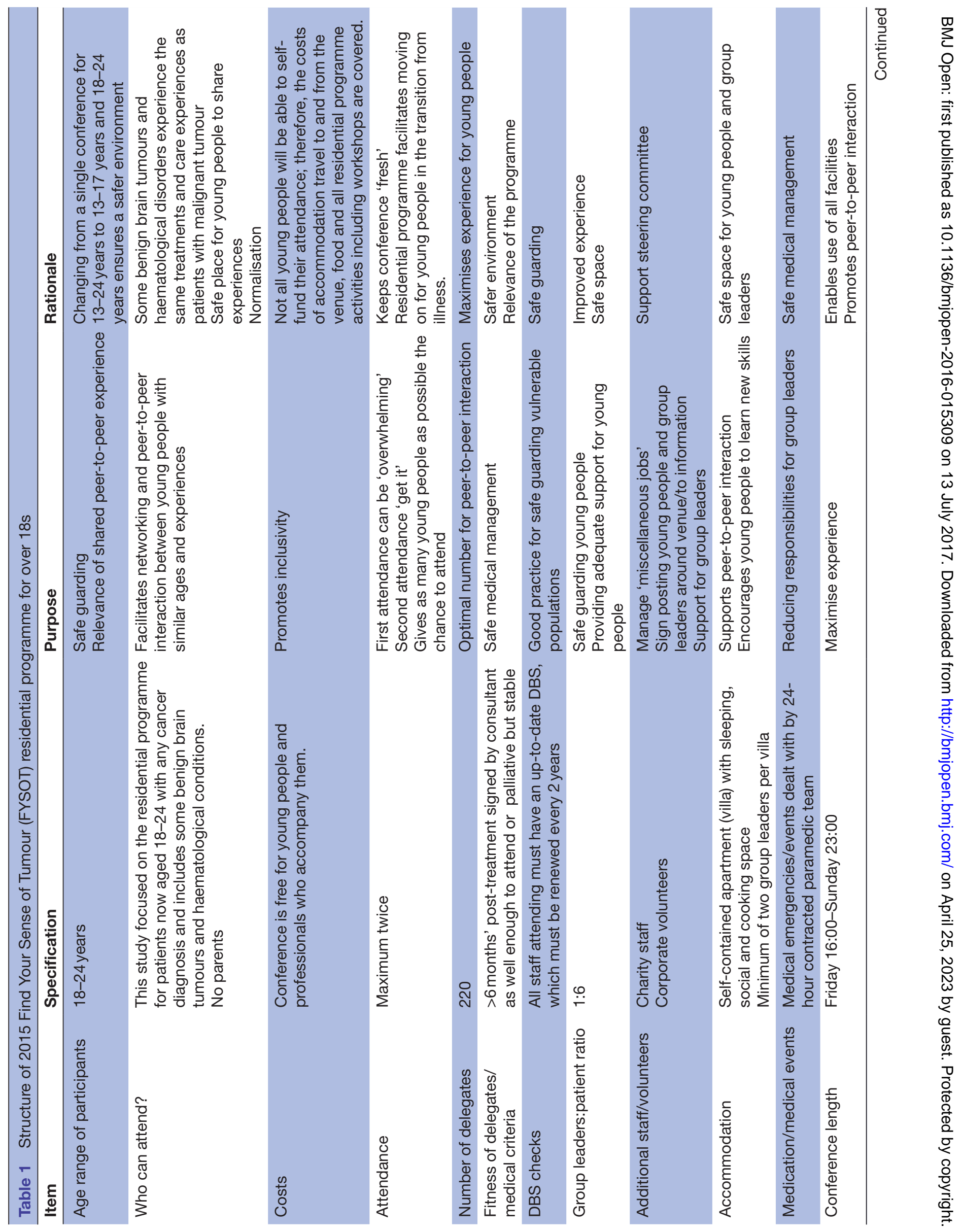




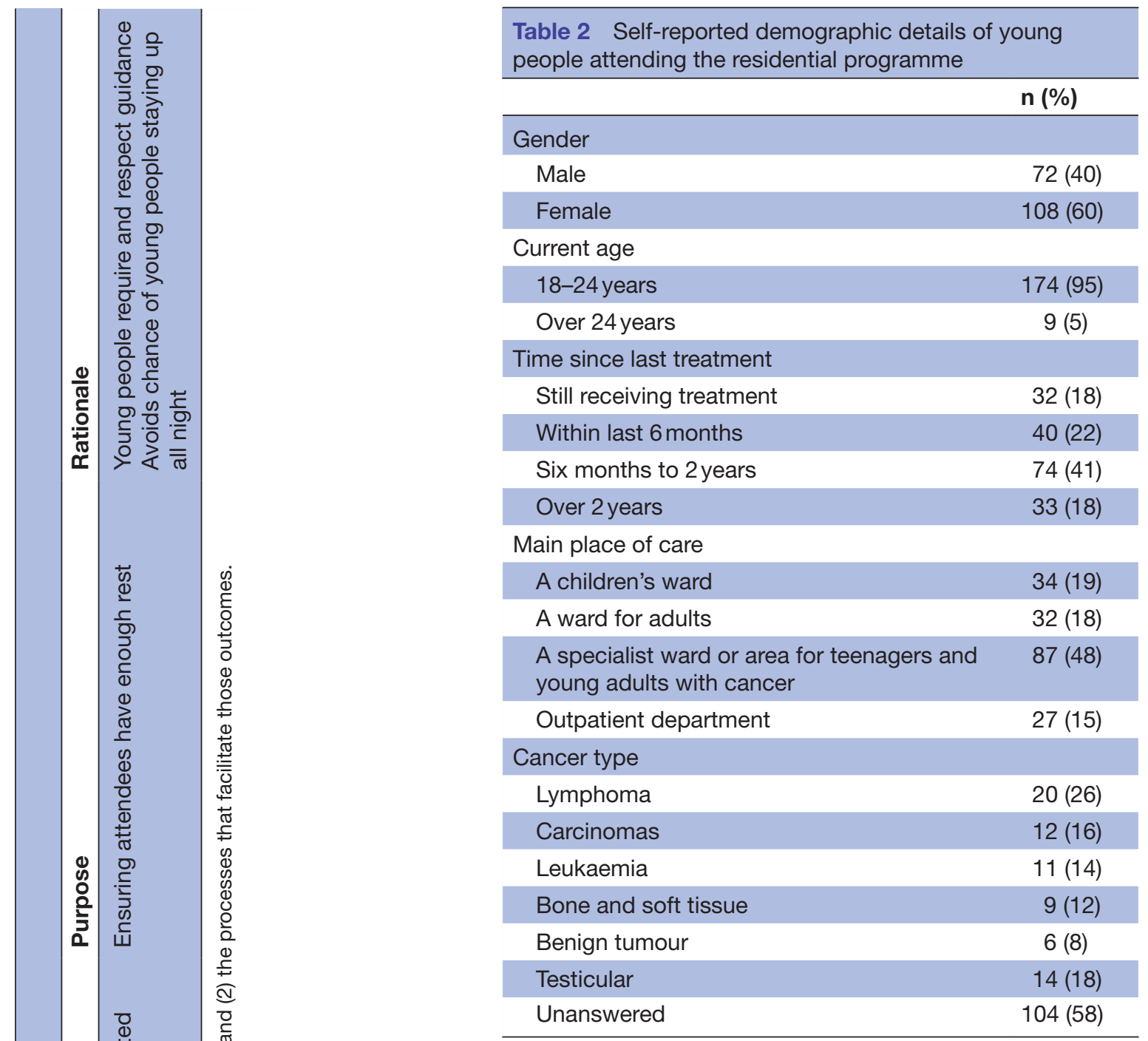

young people benefited, challenges encountered and suggestions for future FYSOT management (Topic Guide, online supplementary appendix 2 ). Interviews were digitally recorded (duration between 31 and $96 \mathrm{~min}$ ) and transcribed verbatim.

Observations focused on peer-to-peer interactions between young people and also between young people and professionals (observations conducted over 29 hours). A coding sheet developed to assist with the accuracy of the observations included actors, location, time of day, time spent observing, the activity observed and interactions ${ }^{22}$ (online supplementary appendix 3 ).

\section{Data analysis}

The framework approach was used to analyse transcripts and observation field notes, which was a flexible and rigorous approach to team analysis. ${ }^{23}$ This method involves charting and sorting data into a framework to facilitate comparisons and interpretation of the key ideas and themes emerging from data. Five key stages are closely interlinked ${ }^{24}{ }^{25}:$ (1) familiarisation of the data, (2) identifying a thematic framework, (3) indexing, (4) charting and (5) mapping and interpretation 


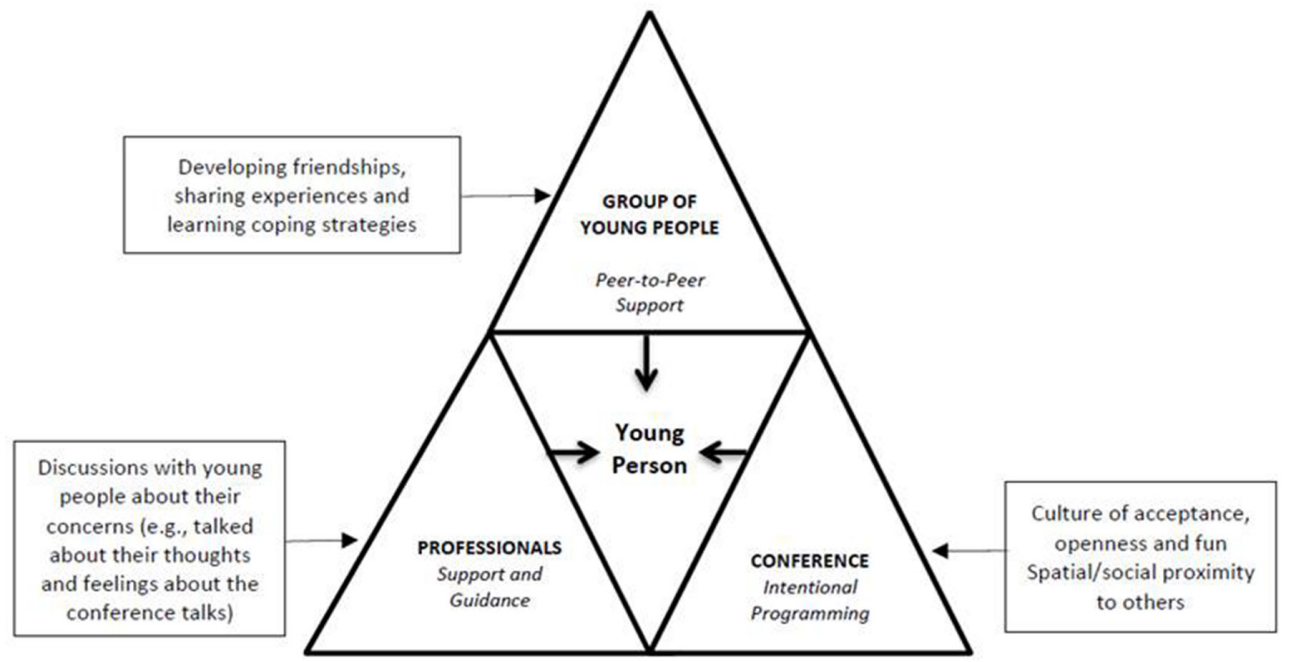

Figure 1 Diagram of Find Your Sense of Tumour residential programme influencing factors.

(online supplementary appendix 4). Analysis was undertaken by one researcher (AM) and validated by two researchers (RMT, LF). We compared and contrasted the data elicited from interviews as well as from observations. Efforts were made to search for alternative themes, divergent patterns and rival explanations to enhance credibility. ${ }^{26}$

Interviewees' quotes are presented in italic, followed by participant number.

\section{RESULTS}

Analysis of interviews and observations identified the key outcomes and influencing factors. As represented in figure 1, three interlinked influencing factors were identified: being with other young people, the professionals accompanying young people to the residential programme and the conference/intentional programming. These three influencing factors contributed to the identified outcomes: positive attitudes, belonging, recreation and increased knowledge for young people.

Although the focus of the residential programme is on young people, interviewees also reflected on the impact of the programme on professionals (described last in this section).

\section{Outcomes}

Positive attitudes: change in interactions over the weekend

Interviewees described an increase in young people's sociability and confidence over the weekend. When young people arrived at the venue, they were described as shy and withdrawn, but as they settled in and attended the first social activity — the DJ on Friday night — young people became more sociable and outgoing. Interviewees described this pattern and its repetition at previous FYSOT.

"I think you can see an immediate impact in which young people, while they're there, will really come out of their shells (...) our young people that have really low self-esteem, you can just see them throughout the weekend blossoming." (019)

The observations corroborated this theme. For example, on Friday young people remained at their dining tables and danced later in the evening; on Sunday, dancing and socialising with other groups occurred immediately away after dinner (online supplementary appendix 1 shows programme). Another example was observed in the increased numbers of young people recording videos at JTV Big Brother chair as the weekend progressed. They shared how they had met and become friends with other young people over the weekend. Young people from different groups were observed interacting as a result of a quiz activity aimed at learning information about other groups; one individual in particular was observed on Friday evening first alone in the lounge area, then alone at the table, not smiling and then being invited by other young people to participate in the quiz. Following this, they were then observed dancing and connecting with other young people on that and subsequent nights.

When reflecting on the weekend at FYSOT, interviewees shared that FYSOT helped young people build their confidence or how it had given them back their confidence.

\section{Belonging: you are not alone}

FYSOT gives young people an opportunity to be with other young people with cancer and feel accepted and understood, which may not happen outside the programme, as described here:

"their normal friends don't understand them, they don't get it whereas their cancer friends, as they put it, they do. They understand where they are coming from, they understand the issues that they have." (006)

Young people described that at FYSOT they did not have to explain why they had not completed their school exams (eg, General Certificate of Secondary Education 
(GCSEs)) or why they may nap in the afternoon (eg, due to fatigue).

Interlinked with this was a sense of freedom of being allowed to be themselves. The shared experience of a cancer diagnosis allowed them to talk about who they were as a person:

"I think it socialises them with other people in the same shoes as them (...) with other young people that can empathise and can understand (...) it just cuts their story short and they can get on with being themselves and not having to explain themselves." (013)

Young people described two worlds, the "cancer world" and the "normal world". Professionals and young people discussed this paradox of feeling normal, not the odd one at FYSOT compared with feelings of not belonging in the outside (normal) world.

"just having a really good time (...) They didn't have to worry that, you know, they had one leg, or they didn't have their hair, because everybody was in the same situation, and you didn't have to think about that at all." (004)

This concept was repeated throughout the weekend, the idea of not being alone, having cancer friends and belonging.

"I think they can often feel really isolated in, you know, their school friendships, or social friendships (...) and they meet somebody else that's going through something similar to them, that's a really powerful thing (...) a lot of young people will say, 'I wouldn't have made it through this without my cancer friends." (019)

Professionals shared how young people discovered during FYSOT that recovery was not just physical but also involved social interaction, peer and psychosocial support. Being at the residential programme, meeting other young people and learning how they had coped with challenges allowed young people to benefit and learn from the shared experience of others.

Young people mentioned FYSOT helped to address issues they had not thought about before, as there had not been space outside the programme for them to reflect on their experiences and deal with emotions. While it could be difficult to express feelings due to the desire to protect their family, the shared experiences at FYSOT allowed young people the freedom to explore and understand their experiences and emotions freely. For example, a young person shared it was like "looking at someone and recognising what you had been through." Humour also connected "cancer friends", as observed in a video recorded by a group on Saturday — young people shared how cancer jokes to the "outside world" could seem offensive; however, at FYSOT it allowed a sense of normalcy, which they valued.

\section{Recreation: having fun and trying new activities}

The intensity of emotions and experiences was balanced by exposure to (new) recreational and leisure activities.
For some, attending FYSOT was their first experience of being away from family (first time ever or first time since diagnosis) and with other young people. A weekend of sharing living spaces with a group of other young people (and professionals) allowed exposure to cooking, cleaning or simply making a cup of tea.

Social activities included a DJ, a paying bar, Big Brother chair, photo booth, chill out area, workshops (eg, make-up, jewellery making), complimentary therapies (eg, massages) and swimming (online supplementary appendix 1).

The consumption of alcohol is permitted by young people at the over 18s programme, as it is believed to facilitate normalisation of experiences in a safe environment (they could drink but were monitored and supported by professionals).

"we had an eighteen-year-old boy who'd never been out (...) it was the first time ever, he'd stood there at a bar, with a male friend (...) and had a drink. He will say to this day, that was his most amazing experience, because he was doing something that a normal young man did (...) we were monitoring and working with him." (018)

Increased knowledge: learning from talks and other young people From inception FYSOT has included young people sharing their story on the main stage. The benefit of this was acknowledged in the interviews:

"I think it's just seeing another young person get up and speak about, kind of, thoughts and feelings and fears and anxieties that they have (...) seeing other young people who are, you know, fit and well and healthy, or sometimes not, getting up and speaking about experiences that they've also had." (010)

Listening to other young people sharing their experience was powerful and empowering, as one interviewee described "they come away feeling reassured, and feeling positive that they can do things" (017). However, there were potential caveats to listening to others' stories, such as feelings of "survivors' guilt" (eg, when young people who had relapsed or were palliative shared their stories). Professionals were aware of this and were there to support young people.

Learning took place through the formal presentations and informally through sharing of experiences and coping strategies between young people. One young person from the steering committee described:

"So it's just like little insider tips that you get to know about (...) it's the link to the cancer community (...) which I think people definitely take away from it, whether it be the directly educational stuff from the talks, or whether it just be talking to other patients." (026)

Learning from others "down the line" or that "have come out the other side" was repeated in the interviews, shared in some presentations and also in peer-to-peer interactions observed. Young people were inspired to see 
someone with a similar diagnosis "further down the line"; it offered hope and practical examples of how to cope with emerging issues and emotions:

"listen to people that have gone through that with them, and have come out the other side, and given them advice of how they did it." (019)

The structured presentations were catalysts for young people to share and discuss their views with other young people and professionals accompanying them when they went back to their chalets. For example, in this FYSOT the topic of death and dying was approached in two plays and the conversations that followed were very difficult, but it gave the opportunity for young people to talk about friends they had lost and about their feelings.

Similarly, presentations on relationships and fertility facilitated discussions about young people's concerns about fertility and offered advice on who to contact when they went back home. Sexuality was a topic discussed during presentations and also in the safe environment of the group chalets with other young people who understood them and professional support (eg, young people discussed fears about disclosing their cancer to potential romantic partners).

\section{Processes}

Analysis identified the key outcomes of the residential programme: positive attitudes, belonging, recreation and increased young people's knowledge. These outcomes were facilitated by three interlinked processes: being with other young people, the support and guidance from professionals accompanying them, and the conference-intentional programming.

\section{Being with other young people: spatial proximity to others}

Interviewees described how young people prior to FYSOT might have had limited peer contact "so they truly could be the one teenager stuck in a side room (...) Just over the course of the weekend, him realising that there were other people his age with the same disease, and they were doing okay (...) The change in him was quite impressive, and from that it just carried on" (015).

Being in a room with other young people with cancer $(\mathrm{n}=200)$ was described as overwhelming, astonishing and empowering:

"I could see (...) how excited they were, how impressed and amazed they were, to walk into a room where there were that many young people that they could relate to." (019)

This context allowed young people to share their feelings: "You know that no-one's judging you, so they're all allowed to be very emotionally free" (001); feel positive, confident, relaxed and accepted. The empowering effect of being with other young people and the respite from limiting beliefs and being self-conscious about their body image is illustrated in this example:

"she hadn't been swimming since she's had her cancer diagnosis (...) people were taking their wigs off and leaving them at the side of the pool. Everyone just jumped in and everyone had scars and bald heads and all that, but it was just the first time for her that it just didn't matter (...) It was just really an inspirational moment for her. That's what Find Your Sense of Tumour is all about. It's just about being yourself and remembering who you are as a person." (012)

\section{Support and guidance from professionals}

The role of accompanying professionals was pivotal to the impact FYSOT had on young people. Professionals invited, organised, accompanied and supported young people throughout. The level of support and preparation prior to the event varied between hospitals. Some professionals organised activities prior to the programme to engage and support young people; this was viewed as potentially improving young people's experience at the event. During the event, professionals were observed guiding young people, showing them what they could do and what was available.

Although not all professionals shared the chalet with young people, there was a shared belief that being present allowed better support for young people, improved their relationship with the group and contributed to their knowledge of how young people support each other and what their needs were.

"they'd built up a good relationship with each other, and with us, that we weren't going to judge them, and they weren't going to judge each other. That's what the weekend created, it created a really good bond, and it gave them the confidence to talk about things that are a bit difficult." (003)

Professionals were advocates for young people and fed back concerns/problems to organisers at regular meetings throughout FYSOT.

\section{Conference-intentional programming}

The three key elements of the residential programme were peer-to-peer support, having fun and learning; as one participant described, FYSOT is "about them [young people] having a good time. Having a good time most of all, meeting other people. Learning about what's going on with them" (020).

Intentional programming had young people at its core. Young people's feedback was part of the residential programme and contributed to changes in it (eg, the balance between presentations and free time changed throughout the years as a result of young people's feedback).

There was a culture that emphasised respect, caring, acceptance and fun through listening, treating young people as capable, providing empathy and connection. This professional shared young people's feedback:

\section{"they felt like they were treated as adults, they felt like they were respected and the information was given in a funny way. It was really useful information and it was fun." (006)}

Observations supported this. On arrival, young people were received by friendly, welcoming volunteers and 
organisers who guided and informed them. The culture of acceptance and support was also observed between young people, who were from the onset supporting others with mobility constraints. This extended to the dance floor, where groups were observed dancing with those in wheelchairs.

Communication on stage was also relaxed. A further example of the relaxed and fun environment was the showcase (online supplementary appendix 1 ) performed on the second night.

\section{"the showcase (...) clapping and cheering on other cities (...) there's just always a really nice feel in the room when we do that." (019)}

Observations recorded during evenings included young people, volunteers and organisers smiling and laughing, a relaxed environment, with dancing and singing.

Fun was also considered integral to presentations as described here:

"I think fun is essential (...) it lightens the mood and it makes you listen and learn more when the serious things come in." (017)

Education during the event was balanced between topics covered and presenters (young people sharing their experience, professionals and inspirational/motivational speakers). For example, on Saturday a young person did a presentation on mental health difficulties after treatment and how to seek help, followed by handset questions and a presentation with a specialist on fertility focused on the effects of chemotherapy on fertility (see online supplementary appendix 1 for more details on presentations). Attendance on Saturday was packed with full attention from young people, with fluctuations on Sunday. Young people also shared their views during three sets of handset questions that allowed immediate visualisation of the group answers to topics previously identified as relevant to young people and used for consultation and research planning.

\section{Professionals}

Outcomes also emerged for professionals accompanying young people. Professionals experienced renewed motivation and passion, and this was facilitated by the relaxed and fun environment: "it was kind of a reminder that, actually, it is worth those really tough, emotionally draining days, when you've got your group laughing and dancing" (003).

Moreover, a strong component of learning existed for professionals:

\section{"I also think for volunteers and for staff and healthcare professionals, it's the increased knowledge about how cancer affects young people and if that's body image, or confidence, or relationships, or fertility." (014)}

Learning from listening to young people was considered a powerful training method. In some cases, this was translated into changes in practice and development of support specific to young people's needs.
"Young people were speaking about the mental health talk (...) So now what I'm going to try and do is work with a mental health professional to design a workshop or programme for our patients." (010)

FYSOT is also a networking opportunity for professionals. However, some professionals struggled with negotiating time to attend; this may be due to a lack of shared understanding about the event. Instead of being just a fun activity, attending the residential programme contributed to practice and service improvement, namely professionals described following up young people and identifying topics that young people needed support with and how they could support them in practice after FYSOT.

\section{DISCUSSION}

This process evaluation of an educational, social and peerto-peer support residential programme for young people with cancer identified key outcomes for young people positive attitudes, belonging, recreation and increased knowledge; and three overarching facilitating processes - being with other young people, the professionals accompanying them and the conference/intentional programming. Attending the event also had an impact on professionals' motivation, learning and changes in practice.

FYSOT contributed to a greater sense of group identity or community (similar findings have been reported in the literature (eg refs 1617 ). This is a developmentally important task for young people ${ }^{1427}$ who are interrupted by their diagnosis, and although family and friends provide an important and valued source of support, ${ }^{28}$ this support may be insufficient as family and friends may not understand survivors' feelings and experiences. ${ }^{29} 30$ People who have endured a similar stressful life experience may be more effective at providing information or appraisal support. ${ }^{31}$ At FYSOT young people's contact with other young people helped them by reassuring and validating their feelings and thoughts. As they shared similar experiences, they could offer specific guidance and advice. ${ }^{3233}$ The support received by hearing the experience and insights of others who had been diagnosed has been coined as 'experiential support' in a study with young breast cancer survivors. ${ }^{34}$ Furthermore, at FYSOT young people had different opportunities to learn from others, informally and formally, and this information could prepare them for what to expect and directly help them cope more effectively with problems that arise as a result of their cancer.

The facilitating factors identified are consistent with the Development Systems Theory ${ }^{35}$ proposal of contexts that facilitate young people's potential to become fully expressed, which include (1) activities and experiences developmentally appropriate, interesting and engaging, and (2) providing developmental support via interactions with caring people and opportunities for building skills. ${ }^{356}$ Emphasising the normalcy of each young person 
was a core element of FYSOT, and this has been found to be important to a positive residential programme experience. ${ }^{37}$ The role of professionals has seldom been explored in the literature; however, this study illustrates they have a pivotal role on the impact of the event for young people by offering tailored support and facilitating a safe and relaxed environment. This may reflect the unique skill required for caring for young people, which has been recognised specifically for nursing ${ }^{38}$ and also generically for all members of the multidisciplinary team. ${ }^{39}$ This supports previous reports in cancer experience literature: how professionals are critical to facilitating a good experience. ${ }^{4041}$

We were able to identify the main outcomes and processes through triangulation of methods and perspectives, observations, and interviews with professionals accompanying young people, young people from the steering committee and organisers. Nevertheless, this study has a number of limitations, not least the absence of the experience of the young person from the perspective of a number of young people. This study was carried out to provide the evidence to appropriately design a longitudinal evaluation from the perspective of the young people attending, significant others and professionals involved in their care who attend the conference. The results have informed the survey for data collection, and retention rate at the second data collection point is $100 \%$, which we think reflects the understanding of the conference gained during this study.

Further, although the experiences of young people attending the November 2015 conference were not examined extensively, two of the steering committee members interviewed were young people who attended the November 2015 conference and a further two young people from the steering committee had attended previous conferences. We interviewed a number of professionals, some of whom had attended more than once, and their views may have been a collective view of a number of conferences. However, the description of the residential programme reflects the learning of over 14 years' experience of running FYSOT that will inform others planning similar programmes.

However, while analytical processes facilitated robust interpretations, the observations were from a single person. Our protocol detailed that notes taken throughout the residential programme were descriptive and no interpretations would be made until analysis. We acknowledge that the process of recording is in itself an interpretation; however, the researcher visited all settings within the residential programme to capture as many experiences as possible.

Research is needed to systematically identify the benefits of residential programmes so that best practice can be developed and implemented. Future studies should include quantitative and qualitative data collection with large sample sizes and long-term follow-up of participants to determine efficacy of the residential programmes curricula. Our findings extended our understanding of the role of residential programme by identifying the outcomes and facilitating mechanisms. We show that these programmes play an important role in providing participants with social, emotional and informational support, as well as play an important role in redefining normality.

Acknowledgements The authors thank all the professionals who have shared their views with us.

Contributors AM, RMT and LF were involved in developing the protocol. AM conducted the data collection. AM, RMT, LF and SM contributed to the analysis and drafted the manuscript. All authors critically revised and approved the final manuscript.

Funding This study was funded by The Queens Trust and Teenage Cancer Trust, who provided access to the conference but were not involved in study design, data collection, analysis or preparation of this paper. RMT is funded through an NIHR Programme Grant for Applied Research (RP-PG-1209-10013). The views expressed are those of the author(s) and not necessarily those of the NHS, the NIHR or the Department of Health.

Competing interests LF is funded by Teenage Cancer Trust who had no input into study design, analysis or write-up.

Patient consent It was an opt-out process.

Provenance and peer review Not commissioned; externally peer reviewed.

Data sharing statement There are no available unpublished data.

Open Access This is an Open Access article distributed in accordance with the Creative Commons Attribution Non Commercial (CC BY-NC 4.0) license, which permits others to distribute, remix, adapt, build upon this work non-commercially, and license their derivative works on different terms, provided the original work is properly cited and the use is non-commercial. See: http://creativecommons.org/ licenses/by-nc/4.0/

(c) Article author(s) (or their employer(s) unless otherwise stated in the text of the article) 2017. All rights reserved. No commercial use is permitted unless otherwise expressly granted.

\section{REFERENCES}

1. Warner EL, Kent EE, Trevino KM, et al. Social well-being among adolescents and young adults with Cancer: a systematic review. Cancer 2016;122:1029-37.

2. Zebrack B, Isaacson S. Psychosocial care of adolescent and young adult patients with Cancer and survivors. J Clin Oncol 2012;30:1221-6.

3. Hokkanen $\mathrm{H}$, Eriksson E, Ahonen O, et al. Adolescents with Cancer: experience of life and how it could be made easier. Cancer Nurs 2014;27:325-35.

4. Bellizzi KM, Smith A, Schmidt S, et al. Adolescent and young adult Health Outcomes and patient experience (AYA HOPE) Study Collaborative Group. positive and negative psychosocial impact of being diagnosed with Cancer as an adolescent or young adult. Cancer 2012;118:5155-62.

5. Geue K, Schmidt R, Sender A, et al. Sexuality and romantic relationships in young adult Cancer survivors: satisfaction and supportive care needs. Psychooncology 2015;24:1368-76.

6. Grinyer A. The biographical impact of teenage and adolescent Cancer. Chronic IIIn 2007;3:265-77.

7. Martiniuk A, Silva M, Amylon M, et al. Camp programs for children with Cancer and their families: review of research progress over the past decade. Pediatr Blood Cancer 2014;61:778-87.

8. Rosenberg RS, Lange W, Zebrack B, et al. An outdoor adventure program for young adults with Cancer: positive effects on body image and psychosocial functioning. J Psychosoc Oncol 2014;32:622-36.

9. McLaughlin M, Nam Y, Gould J, et al. A videosharing social networking intervention for young adult Cancer survivors. Comput Human Behav 2012;28:631-41.

10. Elad $P$, Yagil $Y$, Cohen L, et al. A jeep trip with young adult Cancer survivors: lessons to be learned. Support Care Cancer 2003;11:201-6.

11. Hicks MD, Lavender R. Psychosocial practice trends in pediatric oncology. J Pediatr Oncol Nurs 2001;18:143-53. 
12. Bluebond-Langner M, Perkel D, Goertzel T, et al. Children's knowledge of cancer and its treatment: impact of an oncology camp experience. J Pediatr 1990;116:207-13.

13. Bluebond-Langer M, Perkel D, Goertzel TG. Pediatric Cancer patients' peer relationships: the impact of an oncology camp experience. J Psychosoc Oncol 1991;9:67-80.

14. Zebrack BJ, Oeffinger KC, Hou P, et al. Advocacy skills training for young adult Cancer survivors: the Young adult Survivors Conference at Camp Māk-a-Dream. Support Care Cancer 2006;14:779-82.

15. Gillard A, Watts CE. Program features and developmental experiences at a camp for youth with Cancer. Child Youth Serv Rev 2013;35:890-8.

16. Stevens B, Kagan S, Yamada J, et al. Adventure therapy for adolescents with Cancer. Pediatr Blood Cancer 2004;43:278-84.

17. Meltzer LJ, Bennett Johnson S, Johnson SB. Summer Camps for Chronically III Children: a Source of Respite Care for Mothers. Children's Health Care 2004;33:317-31.

18. Gillard A, Allsop J. Camp experiences in the lives of adolescents with serious illnesses. Child Youth Serv Rev 2016;65:112-9.

19. Hewett-Avison S. Find Your Sense of Tumour Under 18. Brief Report. London: Teenage Cancer Trust, 2015.

20. Yin RK. Case study research: design and methods. 3rd ed. California CA: Thousand Oaks, 2003.

21. Stake RE. Case Studies. In: Denzin NK, Lincoln NK, Handbook of Qualitative Research. Thousand Oaks, California: Sage Publications, 2000:435-54

22. Spradley JP. Participant observation. New York: Holt, Rinehart and Winston, 1980

23. Parkinson S, Eatough V, Holmes J, et al. Framework analysis: a worked example of a study exploring young people's experiences of depression. Qual Res Psychol 2016;13:109-29.

24. Ritchie J, Lewis N, McNaughton N, et al. Qualitative research practice: a Guide for Social Science students and researchers. London: Sage Publications, 2014

25. Spencer L, Ritchie J, Lewis J, et al. Quality in qualitative evaluation: a framework for Assessing Research evidence the Cabinet Office, London. 2003. http://www.civilservice.gov.uk/wp-content/uploads/ 2011/09/a_quality_framework_tcm6-38740.pdf (Accessed 11.08.16).

26. Patton M. Qualitative Research and Evaluation Methods. CA: Sage Publications, 2002.

27. Zebrack B, Bleyer A, Albritton K, et al. Assessing the health care needs of adolescent and young adult Cancer patients and survivors. Cancer 2006;107:2915-23.

28. Zebrack BJ, Mills J, Weitzman TS. Health and supportive care needs of young adult Cancer patients and survivors. J Cancer Surviv 2007;1:137-45.
29. Kent EE, Parry C, Montoya MJ, et al. "You're too young for this": adolescent and young adults' perspectives on cancer survivorship. J Psychosoc Oncol 2012;30:260-79.

30. Rabin C, Simpson N, Morrow K, et al. Behavioral and psychosocial program needs of young adult Cancer survivors. Qual Health Res 2011;21:796-806.

31. Thoits PA. Mechanisms linking social ties and support to physical and mental health. J Health Soc Behav 2011;52:145-61.

32. Roberts CS, Piper L, Denny J, et al. A support group intervention to facilitate young adults' adjustment to Cancer. Health Soc Work 1997;22:133-41.

33. Ussher J, Kirsten L, Butow P, et al. What do Cancer support groups provide which other supportive relationships do not? the experience of peer support groups for people with Cancer. Soc Sci Med 2006:62:2565-76.

34. Snyder KA, Pearse W. Crisis, social support, and the family response: exploring the narratives of young breast Cancer survivors. $J$ Psychosoc Oncol 2010;28:413-31.

35. Lerner RM, Lerner JV, Almerigi J, et al. Positive Youth Development, Participation in Community Youth Development Programs, and Community contributions of Fifth-Grade Adolescents: findings from the First Wave of the 4-H study of Positive Youth Development. J Early Adolesc 2005;25:17-71.

36. Lerner RM, Steinberg L. The scientific study of adolescents development: Past, present, and future. In: Lerner RM, Steinberg L, eds. Handbook of adolescent psychology. $2^{\text {nd }}$ ed. Hoboken, NJ: John Wiley \& Sons Inc, 2004:1-12.

37. Swensen TG. A dose of Camp Dost: meeting the psychosocial needs of children with Cancer. Issues Compr Pediatr Nurs 1988;11:29-32.

38. Royal College of Nursing. Competencies: Caring for teenagers and young adults with cancer: a competence and career framework for nursing 2014. Teenage Cancer Trust, London https://www. teenagecancertrust.org/sites/default/files/Nursing-framework.pdf (Accessed 09/09/16).

39. Taylor RM, Feltbower RG, Aslam N, et al. Modified international e-Delphi survey to define healthcare professional competencies for working with teenagers and young adults with Cancer. BMJ Open 2016;6:e011361.

40. Taylor RM, Fern L, Whelan J, et al. "Your Place or Mine?" Priorities for a Specialist Teenage and Young Adult (TYA) Cancer Unit: Disparity Between TYA and Professional Perceptions. J Adolesc Young Adult Oncol 2011;1:145-51.

41. Fern L, Taylor RM, Whelan J, et al. 'The art of age appropriate care': using participatory research to describe young people's experience of cancer. Cancer Nurs 2013;36:E27-38. 